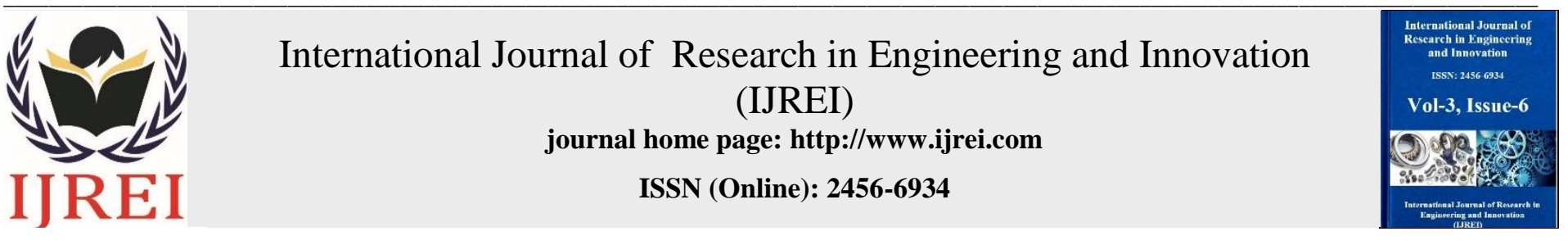

\title{
Optimization of process parameters of friction stir welded joint of AA6061 and AA6082 by response surface methodology (RSM)
}

\author{
Hridya Nand Singh ${ }^{1}$, Amit Kaushik ${ }^{2}$, Deepak Juneja ${ }^{2}$ \\ ${ }^{I}$ M.Tech Scholar, Department of Mechanical Engineering, Geeta Engineering College, Panipat, India \\ ${ }^{2}$ Department of Mechanical Engineering, Geeta Engineering College, Panipat, India
}

\begin{abstract}
The aluminum alloy AA6061 anAA6082 is widely used in the fabrication of lightweight structure with high strength to weight ratio. Friction stir welding is a solid state welding process to overcome the problems encountered in fusion welding. This process uses a non-consumable tool to generate frictional heat on the abutting surfaces. The welding process parameter such as rotational speed, traverse speed and tilt angle play a major role in determining the mechanical properties of welded joint. The present work was designed to identify the most influencing and optimal friction stir welding process parameters on tensile strength and hardness of welded joint of AA6061 and AA6082 using design expert software. Various combination of processing parameters were opt to investigate the optimum values of tensile strength and micro-hardness at nugget zone. The maximum tensile strength (236 MPa) and micro-hardness $(115 \mathrm{HV})$ were found at tool rotation speed $1400 \mathrm{rpm}$, traverse speed $40 \mathrm{~mm} / \mathrm{min}$ with tilt angle $2^{0}$, whereas minimum tensile strength $\left(165 \mathrm{MPa}\right.$ ) was observed at tool rotation speed $800 \mathrm{rpm}$, traverse speed $60 \mathrm{~mm} / \mathrm{min}$ with tilt angle $2^{0}$. In addition, a numerical model and empirical relationship was developed by design expert software between processing parameters (tool rotation speed, traverse speed, and tilt angle) and response surface parameters (tensile strength, percentage elongation and micro-hardness at nugget zone).

Keywords: Friction stir welding, Aluminum alloy, Tensile strength, Microhardness.

\section{Introduction}

Friction stir processing (FSP)/FSW is a method of changing the properties of a metal through intense localized plastic deformation. This deformation is produced by forcibly inserting a non-consumable tool into the work-piece and revolving the tool in a stirring motion as it is pushed laterally through the workpiece. The antecedent of this technique, friction stir welding is used to join multiple piece of metal without creating the heat affected zone typical of fusion welding. Efficient joints in terms of strength of aluminum matrix composite materials cannot be achieved by fusion based welding method due to the reaction between reinforcements and matrices leading to the formation of brittle secondary phase in the weld pool or decomposition of reinforcements on molten metal [1-2]. The characteristics of structure, mechanical properties and microstructure of friction stir welds of $\mathrm{CuZn} 30$ were investigated. Because of not reaching to melting point of metal during welding, evaporation of zinc and copper which makes welding more difficult disappears in friction stir welding [3]. It was found that the correlation between the measured and predicted values of tensile strength, hardness of weld metal better than those of elongation and yield strength. The input parameters of the model consist of weld speed and tool rotation speed [4]. The friction stir welded AA6082-T6 material revealed lower yield and ultimate stresses, and the dissimilar joints displayed intermediate properties. In the tensile test, failure occurred near the weld edge line where a minimum value of hardness was observed [5]. The effect of transverse speed on friction stir welding by using a fully coupled thermos-mechanical model. The stirring effect of welding tool becomes weaker, if transverse speed is high, which is the reason for the occurrence of weld flaw [6]. It was found that the maximum failure load of joints reached $62 \%$ of $\mathrm{Al}-\mathrm{Si}$ alloy base metal with the joints fractured at the interface. The transient phase TiAl forms at the joining interface by Al-Ti diffusion reaction. The formation of $\mathrm{TiAl}_{3}$ is strongly dependent on welding speeds during friction stir welding and thus affects the mechanical properties of joints [7]. The fine weld nugget grain structure of friction stir welds 
undergoes abnormal grain growth in the post weld solution heat treated condition. Once the friction stir welding sheets are subjected to solution heat treatment, the welds experience abnormal grain growth within the surface of the sheet as within the swirl zone [8]. Proposed a 3D numerical model, thermomechanical coupled for friction stir welding to use rigid viscoplastic material description and a continuum assumption for the weld seam. This model is capable of predicting the effect of process parameters on process thermos- mechanics, such as the temperature strain, strain rate as well as material flow and forces [9]. The cold rolled steel joints with the lowest rotation speed (250 rpm) shows the highest minimum hardness and narrowest width of the transition region in all the joints evaluated. The grain size in the stir zone also becomes smaller with decreasing tool rotation speed [10]. The ultimate tensile strength of the welded joint is higher than the parent material and it is directly proportional to the welding speed, welding parameter such as tool rotation, transverse speed and axial force is also effect the welded joint in friction stir welding [11-15]. The microstructure and mechanical properties of the carbon steel joints are significantly affected by the welding conditions. The strength of the S12C steel joints increases with the increasing welding speed [16]. The optimal processing parameters for producing a defect free weld when a rotating threaded weld tool is inserted into a weld and literally stirs the edges of the seam together [17]. The microstructure evolution in a 304 stainless steel weld during friction stir welding were examined. The stir zone and thermosmechanically affected zone showed typical dynamically recrystallized and recovered microstructure, respectively [18]. FSW process led to a decrease of both the proof strength and ultimate tensile strength, equal to $43 \%$ and $28 \%$ respectively, respect to the base material, while the elongation to failure increase of about $64 \%$ [19]. The ultrafine grained microstructure with the mean grain size of $\sim 0.7 \mu \mathrm{m}$ is obtained in the weld nugget by using water cooling. However, The FSW joint exhibits softening compared with the ultrafine grained based material and the heat affected zone (HAZ) has the lowest hardness owing to the coarsening of the strengthening precipitates [20]. Joints fabricated using a tool rotational speed of 1,600 rpm, a welding speed of $0.67 \mathrm{~mm} / \mathrm{s}$, and an axial force of $3 \mathrm{kN}$ yielded superior tensile properties compared to other joints. Fatigue properties less than base metal [21]. It seems that there is a quasi-linear relation between the change of the axial load on the shoulder and the variation of the equivalent plastic strain. The material flow can be accelerated with the increase of the translational and angular velocity [22]. The pore firstly occurred near the welding line at relatively low welding speed, but move into advancing side and up part of the weld when continues to increase the welding speed [23]. The tensile strength of the joint is lower than that of the parent metal and it is directly proportional to the travel / welding speed [24]. The hardness and ultimate tensile strength of bimetallic weld joint was increases by increasing the pre-stresses, and by increasing the thermal loading ductility was decreases. To avoid the brittle failure of carbon steel, the value of thermal stress and pre stress should take low as possible. At plastic range, the shape of stress strain curve of stainless steel is higher than the carbon steel [25-27]. The semi-analytical model can be used to obtain the strains, strain rates, and estimations of the temperatures and micro-hardness in the various weld zones [28-29]. The objective of present work is to optimize the process parameters such as tool rotational speed, traverse speed and tilt angle for obtaining the greater or optimum value of mechanical properties like ultimate tensile strength, micro-hardness of the friction stir welded joint of AA6082 and AA6061.

\section{Methods and Materials}

The Aluminium alloy of AA6061 and AA6082 are selected to fabricate dissimilar joints using friction stir welding (FSW) as shown in fig.1. The length, width and thickness of both the alloy plates are chosen as 120, 40 and $6.3 \mathrm{~mm}$ respectively. The chemical composition of base material AA6061 \& AA6082 and tool steel $\mathrm{H} 13$ are given in table $1 \& 2$. The Processing parameter for friction stir welding were chosen by design expert methods, and 20 experiments was done to get optimum values of tensile strength and micro-hardness of welded joint. The processing parameters table as shown below.

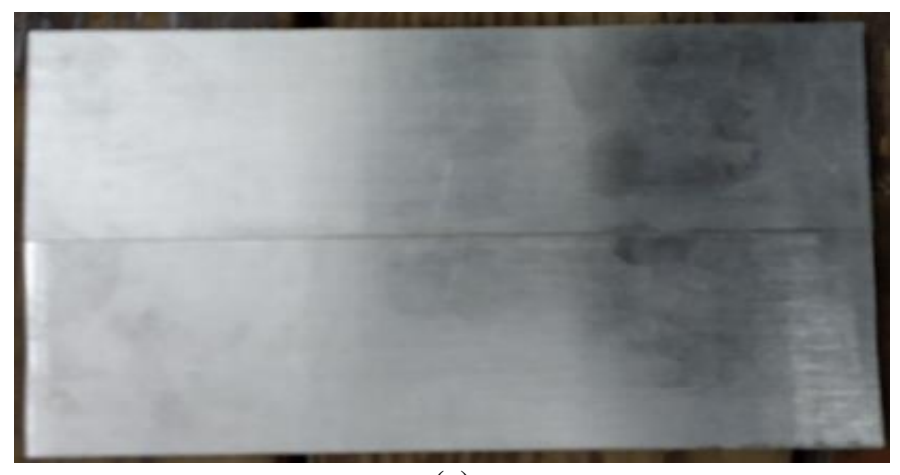

(a)

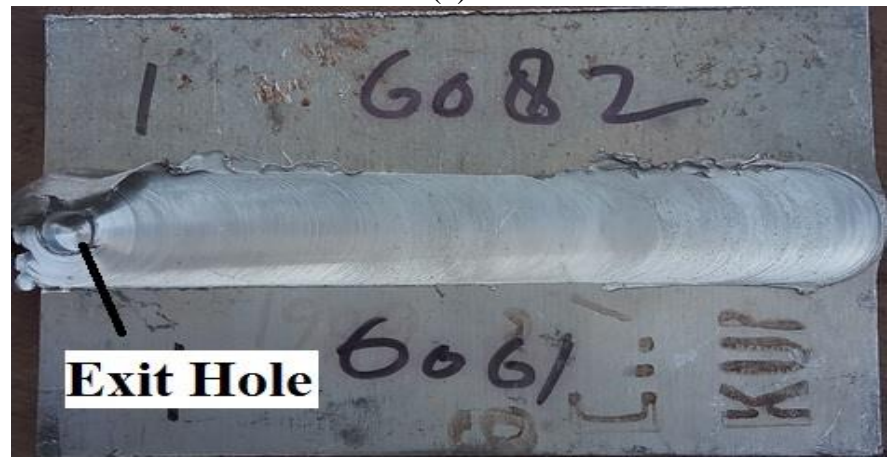

(b)

Figure 1: Base plate, (a) before welding, (b) after welding

Table 1: Chemical composition of base material

\begin{tabular}{|c|c|c|c|c|c|c|c|c|c|}
\hline Al- Alloy & $\mathrm{Si}$ & $\mathrm{Fe}$ & $\mathrm{Cu}$ & $\mathrm{Mn}$ & $\mathrm{Mg}$ & $\mathrm{Cr}$ & $\mathrm{Zn}$ & $\mathrm{Ti}$ & $\mathrm{Al}$ \\
\hline AA6061 & 0.6 & 0.3 & $0.15-0.4$ & 0.1 & $0.8-1.2$ & $0.04-0.35$ & 0.2 & 0.1 & $\mathrm{Balance}$ \\
\hline AA6082 & $0.7-1.3$ & 0.25 & 0.1 & $0.4-1.0$ & $0.6-1.2$ & 0.15 & 0.2 & 0.2 & Balance \\
\hline
\end{tabular}


Table 2: Chemical composition of friction stir welding Tool

\begin{tabular}{|c|c|c|c|c|c|c|c|}
\hline $\mathrm{C}$ & $\mathrm{Cr}$ & $\mathrm{Mn}$ & $\mathrm{Mo}$ & $\mathrm{P}$ & $\mathrm{Si}$ & $\mathrm{S}$ & $\mathrm{V}$ \\
\hline $0.32-0.45$ & $4.75-5.5$ & $0.2-0.5$ & $1.1-1.75$ & $0.03 \max$ & $0.8-1.2$ & $0.03 \max$ & $0.8-1.2$ \\
\hline
\end{tabular}

\section{Results and Discussion}

\subsection{Tensile Strength}

The friction stir welding approach is used to join the different aluminum alloy (AA6061 and AA6082) with different processing parameters like rotational speed (RS), traverse speed (TS) and tilt angle (TA). The optimum combination of processing parameters have been selected with the help of design expert software. There are 20 experiments have been done on the basis of processing parameters. The optimum processing parameters and their responses have been shown in table 3. The ultimate tensile strength is the maximum stress that a material can withstand while being pulled before necking. The tensile test specimens were cut from the welded plate with the help of milling cutter. All tensile stress test were carried out perpendicular to welding direction to calculate the tensile strength of the weldment at room temperature.

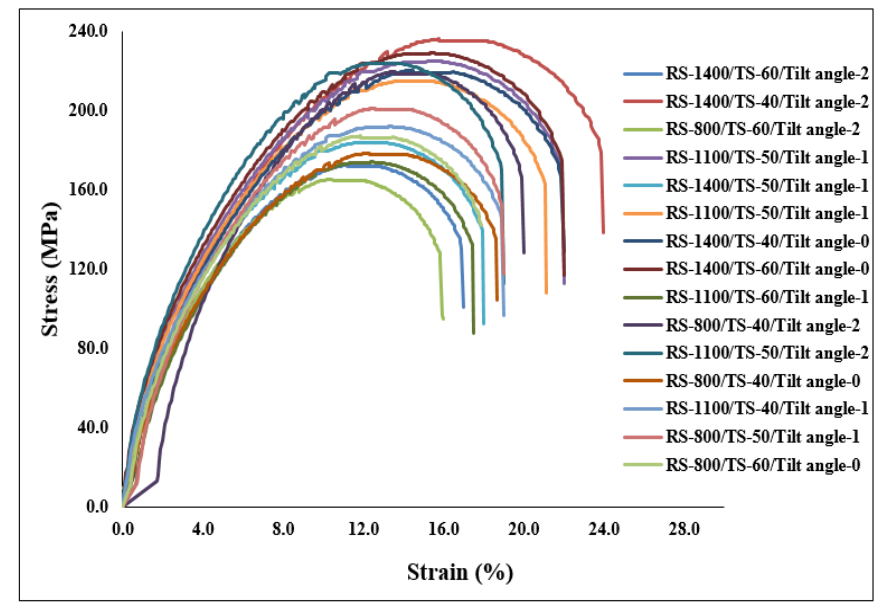

Figure 2: Stress strain diagram of friction stir welded joint of dissimilar Al alloy

The defect free friction stir welded joints are depend upon thermal history and correct processing parameters [30-31]. The coarse grains are found due to the dissolution of fine scale precipitates zone during welding which affect the tensile properties of the welded joint. Fig. 3-4 illustrate the tensile properties of the welded joint of AA6061 and AA6082. It can be noted that the maximum tensile strength i.e. $236 \mathrm{MPa}$ was found at rotation speed of $1400 \mathrm{rpm}$, traverse speed $40 \mathrm{~mm} / \mathrm{min}$ with tilt angle $2^{0}$ as shown in fig.2. The peak tensile properties for the joints within these samples have been obtained at the processing parameter of rotation speed of $1400 \mathrm{rpm}$, traverse speed $40 \mathrm{~mm} / \mathrm{min}$ with tilt angle $2^{0}$ which have tendency to increase the precipitation hardening of the welded joint. The maximum percentage elongation i.e. $24 \%$ and micro-hardness at nugget i.e. $115 \mathrm{HV}$ also found at the same processing parameters as shown in fig. 45. The minimum tensile strength was obtained at rotation speed of $800 \mathrm{rpm}$, traverse speed $60 \mathrm{~mm} / \mathrm{min}$ with tilt angle $2^{0}$. All the fracture occurred at the interface or near the nugget zone (NZ) and thermo mechanically affected zone (TMAZ) on the advancing side (AS). The reason of fracture near to the nugget zone and thermo mechanically affect zone may be resulting in many coarse grains brittle structure near to the NZ and TMAZ [32]. It may be noted that the all joints are fractured at the advancing side, this shows that the tensile strength of these weldment are not same on both side to the weld center, it means the strength of advancing side is weaker than the retreating side (RS).

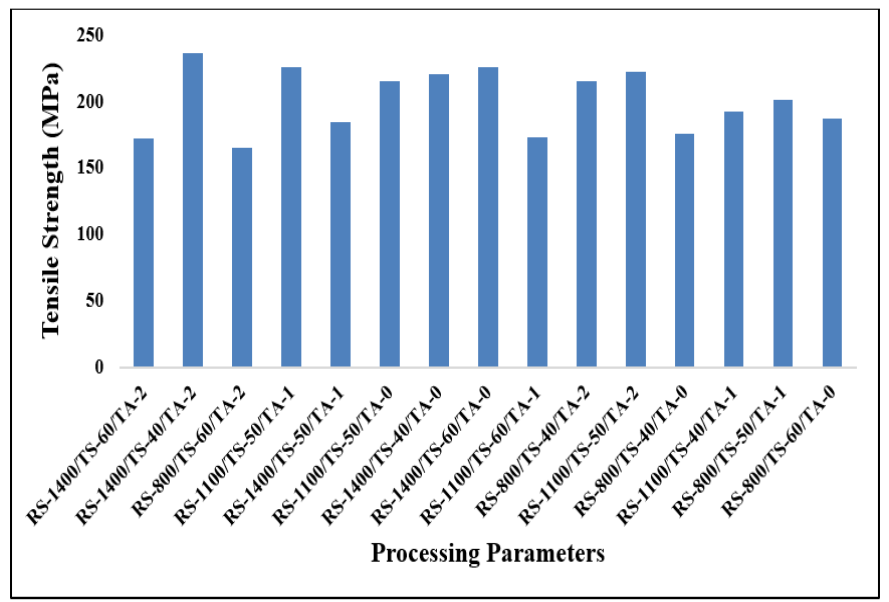

Figure 3: Comparison of tensile strength

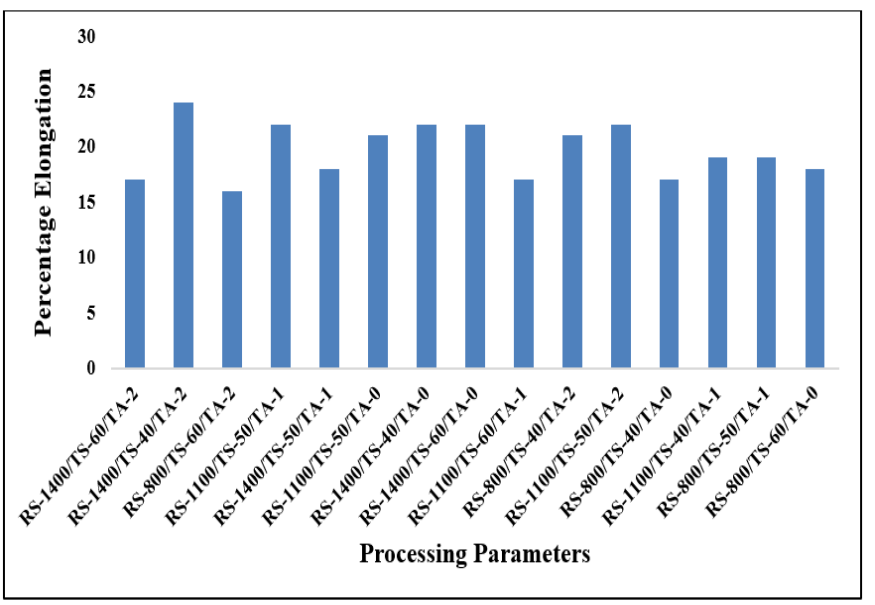

Figure 4: Comparison of percentage elongation

\subsection{Micro-hardness at Nugget zone}

The effect of rotational speed (800-1400 rpm), traverse speed (40$60 \mathrm{~mm} / \mathrm{min})$ and tilt angle $\left(0-2^{0}\right)$ on the micro-hardness at the nugget zone of the welded joint of AA6061 and AA6082 by friction stir welding as shown in fig. 5. The stirred zone (SZ) of friction stir welding have the highest hardness in the welded zone due to the high temperature which results in the dissolution of the 
precipitation phase in that zone. This increase in the hardness at the stirred zone was observed in friction stir welding of other precipitation hardened alloys [33-34]. The low hardness was observed in the thermo mechanically affected zone due to coarsening of the hardening phases in that region. The lowest hardness was observed in heat affected zone (HAZ). The high temperature was observed during welding can induce an over aging, resulting decreases of mechanical properties. The microhardness values at the nugget zone as shown in fig.5. The maximum micro-hardness $(115 \mathrm{HV})$ was found at the processing parameter of rotation speed of $1400 \mathrm{rpm}$, traverse speed 40 $\mathrm{mm} / \mathrm{min}$ with tilt angle $2^{0}$. The hardness value are depend on the precipitates distribution, grain size and dislocation structure. All welded samples, hardness decreases from thermo mechanically affected zone to the parent metal. This was happened that the temperature reached in the thermo mechanically affected zone to heat affected zone was sufficient for the ageing precipitate to be dissolved. The nugget zone experiences a peak temperature between $300-400^{\circ} \mathrm{C}$ [35], which result in a hardness variation.

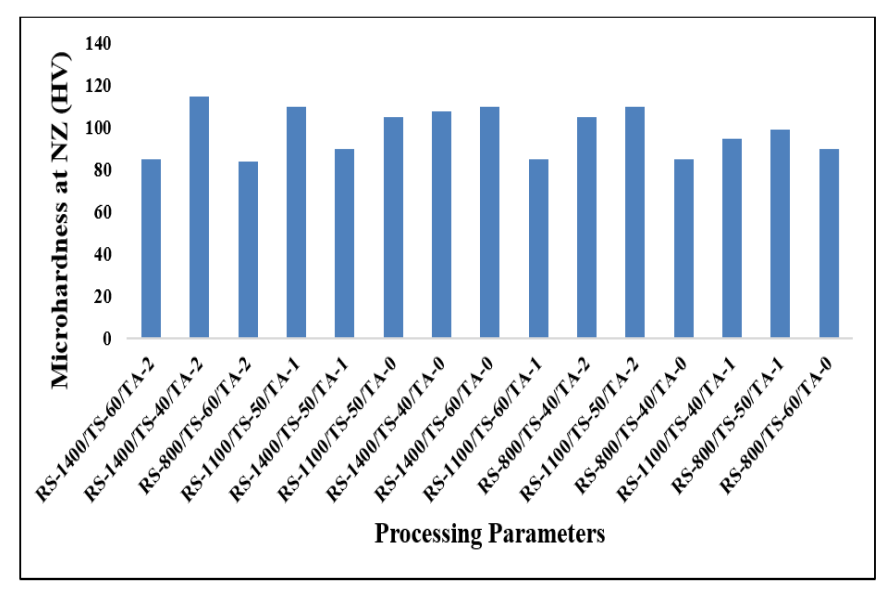

Figure 5: Comparison of micro-hardness at nugget zone

\subsection{Analysis of variance (ANOVA)}

To identify the process parameters that are statistically significant, analysis of variance (ANOVA) test was conducted. The purpose of ANOVA test is to determine the significance of process parameters which affect the mechanical properties of friction stir welded joints. The F-test (Fisher's test) may also be used to determine which process parameter has a significant effect on the mechanical properties. The results of ANOVA test shows that the opt process parameters are highly significant factor affecting the mechanical properties of friction stir welded joint in order to tool rotational speed, traverse speed and tilt angle.

\subsection{Developing a mathematical model}

The empirical relationship was developed for the response variable i.e. ultimate tensile strength, percentage elongation, and micro-hardness at nugget zone under the input processing parameters i.e. tool rotational speed (A), traverse speed (B) and tilt angle (c) using analysis of variance technique with the help of design expert software. The processes parameters for friction stir welded joint for AA6061 and AA6082 and their levels and responses are shown in table 3 . The mathematical empirical relationship for tensile strength, percentage elongation and microhardness at nugget zone are as follow.

Tensile Strength $=-534.36+0.34 \mathrm{~A}+21.34 \mathrm{~B}+73.7 \mathrm{C}-$ $0.00087 \mathrm{AB}-0.0229 \mathrm{AC}-1.637 \mathrm{BC}-0.0001 \mathrm{~A}^{2}-0.1999 \mathrm{~B}^{2}-$ $16.09 \mathrm{C}^{2}$

$\%$ Elongation $=-54.18+0.043 \mathrm{~A}+1.94 \mathrm{~B}+6.96 \mathrm{C}-0.00012 \mathrm{AB}$ $-0.002 \mathrm{AC}-10.1625 \mathrm{BC}-0.0177 \mathrm{~B} 2-1.727 \mathrm{C}^{2}$

Micro-hardness $=-266.46+0.178 \mathrm{~A}+10.37 \mathrm{~B}+35.28 \mathrm{C}-$ $0.0005 \mathrm{AB}-0.0133 \mathrm{AC}-0.725 \mathrm{BC}-0.0963 \mathrm{~B} 2-7.863 \mathrm{C}^{2}$

Table 3: Input processing parameters and their responses

\begin{tabular}{|c|c|c|c|c|c|c|}
\hline Run & A:Tool rotational speed & B:feed rate & C:Tilt angle & Tensile strength & $\%$ Elongation & Micro-hardness \\
\hline & $\mathrm{rpm}$ & $\mathrm{mm} / \mathrm{min}$ & degree & $\mathrm{MPa}$ & $\%$ & $\mathrm{HV}$ \\
\hline 1 & 1400 & 60 & 2 & 172 & 17 & 85 \\
\hline 2 & 1400 & 40 & 2 & 236 & 24 & 115 \\
\hline 3 & 800 & 60 & 2 & 165 & 16 & 84 \\
\hline 4 & 1100 & 50 & 1 & 225 & 22 & 110 \\
\hline 5 & 1400 & 50 & 1 & 184 & 18 & 90 \\
\hline 6 & 1100 & 50 & 0 & 215 & 21 & 105 \\
\hline 7 & 1400 & 40 & 0 & 220 & 22 & 108 \\
\hline 8 & 1100 & 50 & 1 & 204 & 20 & 100 \\
\hline 9 & 1400 & 60 & 0 & 225 & 22 & 110 \\
\hline 10 & 1100 & 60 & 1 & 173 & 17 & 85 \\
\hline 11 & 1100 & 50 & 1 & 215 & 21 & 105 \\
\hline 12 & 1100 & 50 & 1 & 220 & 22 & 108 \\
\hline 13 & 800 & 40 & 2 & 215 & 21 & 105 \\
\hline 14 & 1100 & 50 & 2 & 222 & 22 & 110 \\
\hline 15 & 800 & 40 & 0 & 175 & 17 & 85 \\
\hline 16 & 1100 & 50 & 1 & 232 & 23 & 115 \\
\hline 17 & 1100 & 50 & 1 & 204 & 20 & 100 \\
\hline 18 & 1100 & 40 & 1 & 192 & 19 & 95 \\
\hline 19 & 800 & 50 & 1 & 201 & 19 & 99 \\
\hline 20 & 800 & 60 & 0 & 187 & 18 & 90 \\
\hline
\end{tabular}


The developed models was tested using ANOVA method with the help of design expert software. The ANOVA results for tensile strength, percentage elongation and hardness at nugget zones are shown in table 4-6. The all models gives the highly significant fisher's $F$ value which shows that the model adequately representing the relationship between process parameters and response. The fisher's F value of developed model for tensile strength is 3.508 which shows that the model is significant and there is only $3.17 \%$ chance that a model Fisher's value could occur due to noise. The lack of fit $F$ value of 2.415 shows that the lack of fit is not significant. For a good model lack of fit should be not significant. The residual error value (2184.55) should be the sum of lack of fit (1544.21) and pure error (639.33). By this column of fit summary recommended quadratic model is statically significant for analyzing the tensile stress of welded joint of AA6061 and AA6082.

The fisher's F value of developed model for percentage elongation is 3.648 which shows that the model is significant and there is only $2.80 \%$ chance that a model Fisher's value could occur due to noise. The lack of fit $F$ value of 2.214 shows that the lack of fit is not significant. For a good model lack of fit should be not significant. The residual error value (23.57) should be the sum of lack of fit (16.23) and pure error (7.33). By this column of fit summary recommended quadratic model is statically significant for analyzing the percentage elongation of welded joint of AA6061 and AA6082.

The fisher's $F$ value of developed model for micro-hardness at nugget zone is 3.204 which shows that the model is significant and there is only $4.195 \%$ chance that a model Fisher's value could occur due to noise. The lack of fit $F$ value of 2.12 shows that the lack of fit is not significant. For a good model lack of fit should be not significant. The residual error value (543.13) should be the sum of lack of fit (369.80) and pure error (173.33). By this column of fit summary recommended quadratic model is statically significant for analyzing the micro-hardness at nugget zone of welded joint of AA6061 and AA6082.

Table 4: analysis of variance (ANOVA) test for tensile strength

\begin{tabular}{|c|c|c|c|c|c|c|}
\hline \multicolumn{7}{|c|}{ Tensile strength } \\
\hline Source & Sum of square & df & Mean & F-value & P -value & \\
\hline Model & 6894.248 & 9 & 766.03 & 3.508 & 0.0317 & significant \\
\hline A-Tool rotational speed & 883.6 & 1 & 883.60 & 4.047 & 0.0719 & \\
\hline B-feed rate & 1345.6 & 1 & 1345.60 & 6.162 & 0.0324 & \\
\hline C-Tilt angle & 14.4 & 1 & 14.40 & 0.066 & 0.8025 & \\
\hline AB & 55.125 & 1 & 55.13 & 0.252 & 0.6262 & \\
\hline AC & 378.125 & 1 & 378.13 & 1.732 & 0.2175 & \\
\hline BC & 2145.125 & 1 & 2145.13 & 9.824 & 0.0106 & \\
\hline A $\hat{A}^{2}$ & 270.0227 & 1 & 270.02 & 1.237 & 0.2921 & \\
\hline BA $\hat{A}^{2}$ & 1090.023 & 1 & 1090.02 & 4.992 & 0.0494 & \\
\hline CÂ & 712.0227 & 1 & 712.02 & 3.261 & 0.1011 & \\
\hline Residual & 2183.552 & 10 & 218.36 & & & \\
\hline Lack of Fit & 1544.219 & 5 & 308.84 & 2.415 & 0.1776 & not significant \\
\hline Pure Error & 639.3333 & 5 & 127.87 & & & \\
\hline Cor Total & 9077.8 & 19 & & & & \\
\hline
\end{tabular}

Table 5: analysis of variance (ANOVA) test for percentage elongation

\begin{tabular}{|c|c|c|c|c|c|c|}
\hline \multicolumn{7}{|c|}{ Percentage Elongation } \\
\hline Source & Sum of square & df & Mean & F-value & p-value & \\
\hline Model & 77.37955 & 9 & 8.598 & 3.648 & 0.02802 & significant \\
\hline A-Tool rotational speed & 14.4 & 1 & 14.4 & 6.109 & 0.03301 & \\
\hline B-feed rate & 16.9 & 1 & 16.9 & 7.170 & 0.02318 & \\
\hline C-Tilt angle & $2.84 \mathrm{E}-14$ & 1 & 0.000 & 0.000 & 1.00000 & \\
\hline AB & 1.125 & 1 & 1.125 & 0.477 & 0.50537 & \\
\hline AC & 3.125 & 1 & 3.125 & 1.326 & 0.27634 & \\
\hline BC & 21.125 & 1 & 21.125 & 8.962 & 0.01349 & \\
\hline A $\hat{A}^{2}$ & 4.4545 & 1 & 4.455 & 1.890 & 0.19923 & \\
\hline BÂ & 8.642045 & 1 & 8.642 & 3.666 & 0.08453 & \\
\hline CÂ & 8.204545 & 1 & 8.205 & 3.481 & 0.09165 & \\
\hline Residual & 23.57045 & 10 & 2.357 & & & \\
\hline Lack of Fit & 16.23712 & 5 & 3.247 & 2.214 & 0.20173 & not significant \\
\hline Pure Error & 7.333333 & 5 & 1.467 & & & \\
\hline Cor Total & 100.95 & 19 & & & & \\
\hline
\end{tabular}


Table 6: analysis of variance (ANOVA) test for micro-hardness at nugget zone

\begin{tabular}{|c|c|c|c|c|c|c|}
\hline \multicolumn{7}{|c|}{ Micro-hardness } \\
\hline Source & Sum of square & $\mathrm{df}$ & Mean & F-value & p-value & \\
\hline Model & 1566.064 & 9 & 174.007 & 3.204 & 0.04195 & significant \\
\hline A-Tool rotational speed & 202.5 & 1 & 202.500 & 3.728 & 0.08231 & \\
\hline B-feed rate & 291.6 & 1 & 291.600 & 5.369 & 0.04299 & \\
\hline C-Tilt angle & 0.1 & 1 & 0.100 & 0.002 & 0.96662 & \\
\hline $\mathrm{AB}$ & 18 & 1 & 18.000 & 0.331 & 0.57756 & \\
\hline $\mathrm{AC}$ & 128 & 1 & 128.000 & 2.357 & 0.15576 & \\
\hline $\mathrm{BC}$ & 420.5 & 1 & 420.500 & 7.742 & 0.01937 & \\
\hline $\mathrm{AA}^{2}$ & 72.551 & 1 & 72.551 & 1.336 & 0.27465 & \\
\hline $\mathrm{BA}^{2}$ & 255.36 & 1 & 255.364 & 4.702 & 0.05533 & \\
\hline $\mathrm{CA}^{2}$ & 170.05 & 1 & 170.051 & 3.131 & 0.10725 & \\
\hline Residual & 543.13 & 10 & 54.314 & & & \\
\hline Lack of Fit & 369.80 & 5 & 73.961 & 2.133 & 0.21264 & not significant \\
\hline Pure Error & 173.33 & 5 & 34.667 & & & \\
\hline Cor Total & 2109.2 & 19 & & & & \\
\hline
\end{tabular}

\subsection{Optimization of process parameters}

Response surface method (RSM) is used an optimization tool to obtained the optimum values of the process parameters. Design expert software is used to optimize the process parameters. For this purpose contour plots and 3D response surface graph are made based on the model developed by considering the optimum process parameters. The optimum tensile strength, percentage elongation and micro-hardness at nugget zone of friction stir welding joint of AA6061 and AA6082 is exhibited by the peak of response surface as shown in fig. 6-8.

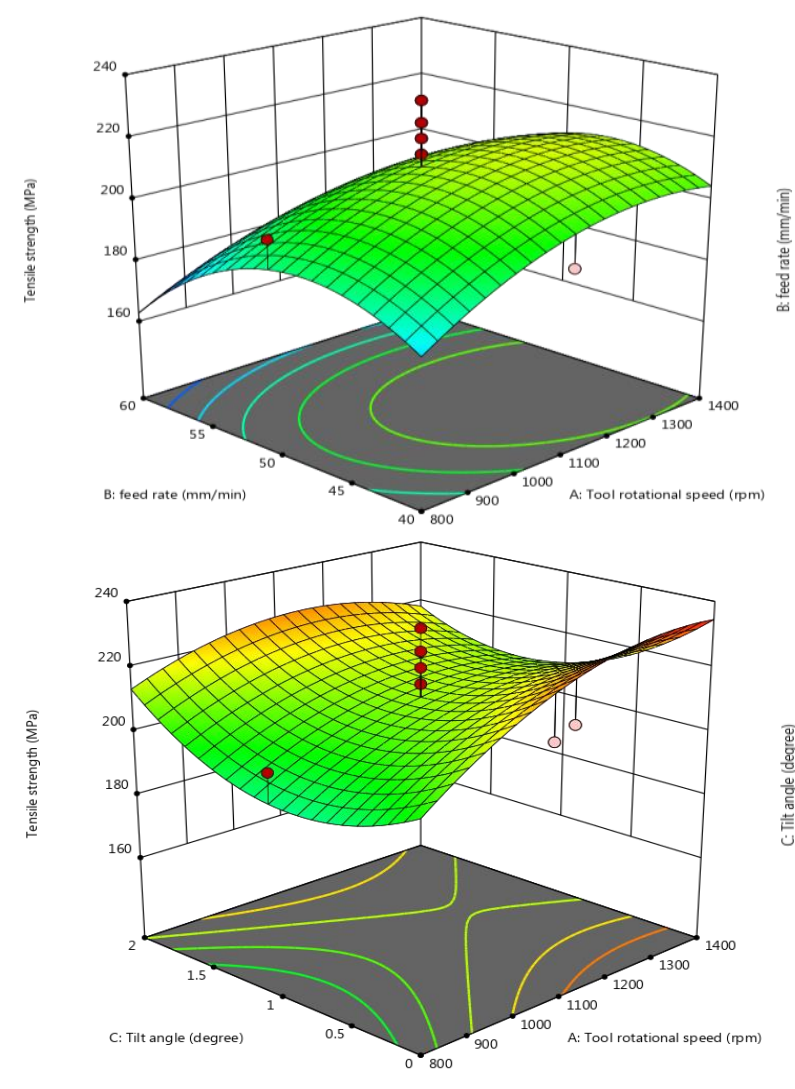

When the tool rotational speed increases, then the tensile strength also increases due to strain hardening effect induced by tool stirring, whereas excess heat input play the predominant role at high tool rotation speed such lower tensile strength was observed when the tool rotation increases. As the feed rate increases then tensile strength first increases then decreases. The minimum tensile strength was found at lower tool rotation speed due to inadequate tool stirring action [36-37]. The maximum tensile strength $(236 \mathrm{MPa})$ was observed at tool rotation $1400 \mathrm{rpm}$, traverse speed $40 \mathrm{~mm} / \mathrm{min}$ with tilt angle $2^{0}$.

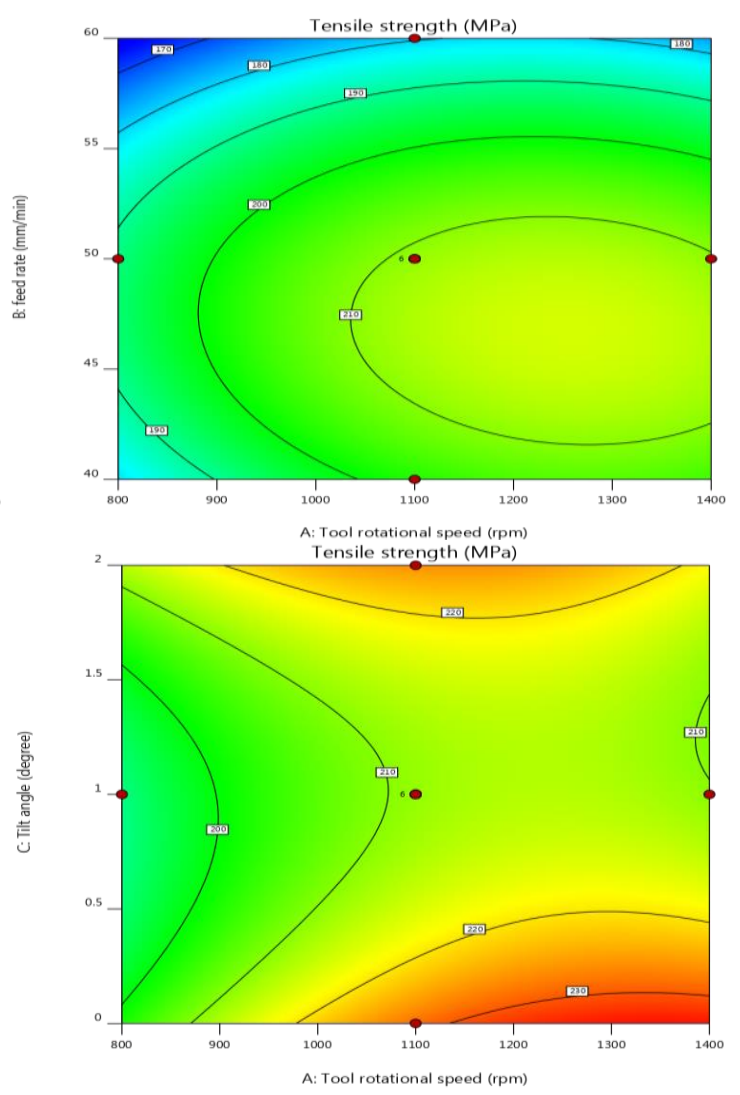



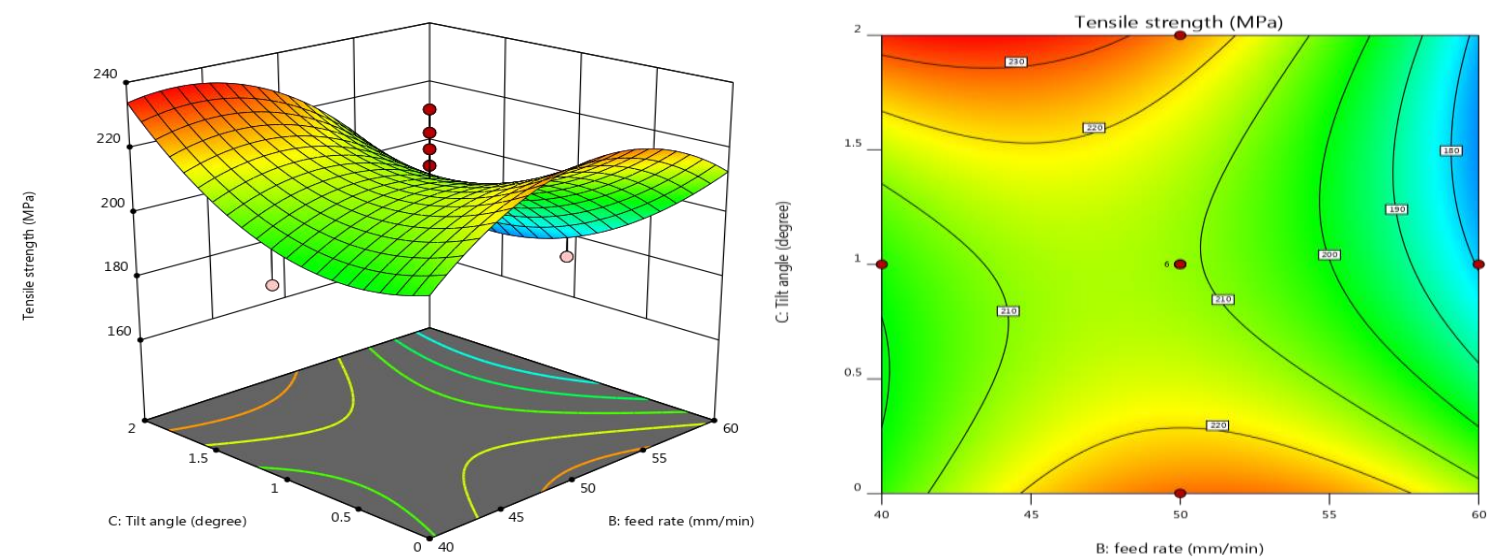

Figure 6: 3D response surface plot and contour plot for tensile strength of FSW joint of AA6061 and AA6082
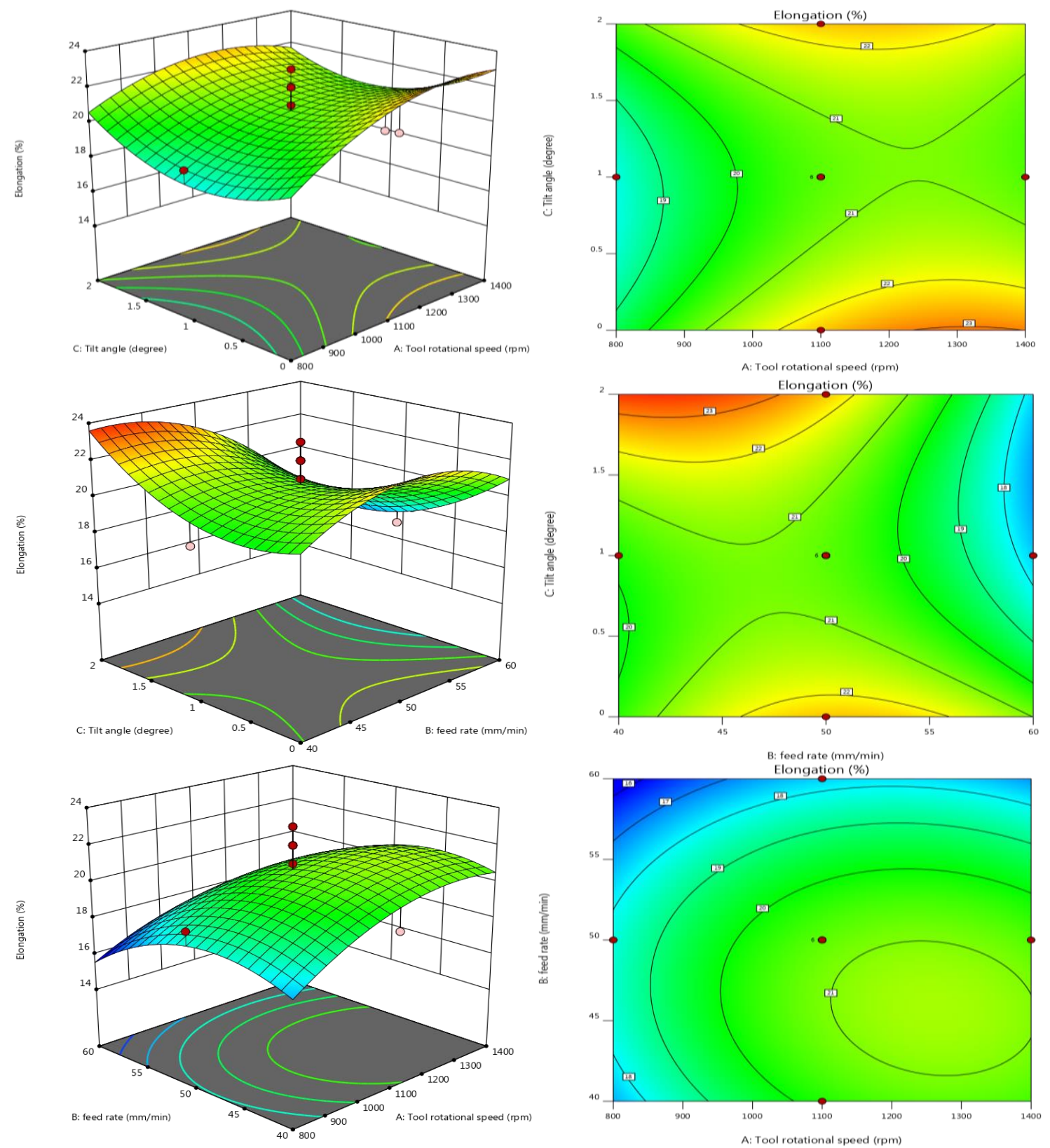

Figure 7: 3D response surface plot and contour plot for percentage elongation of FSW joint of AA6061 and AA6082 

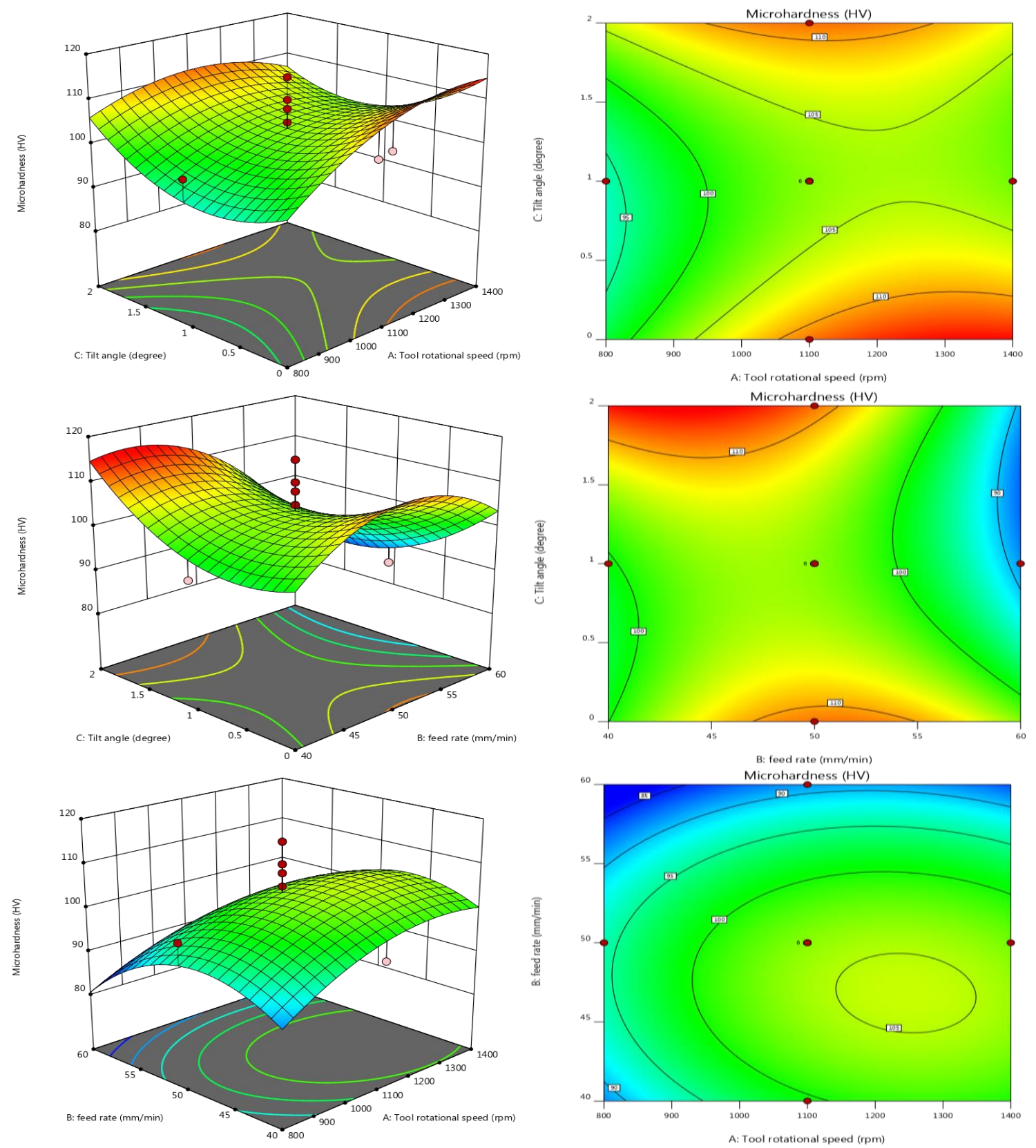

Figure 8: 3D response surface plot and contour plot for micro-hardness at nugget zone of FSW joint of AA6061 and AA6082

When the feed rate or traverses speed increases, the tensile strength and hardness also increases up to a certain value. Large heat was found in the welded region at lower welding traverse speed. As the traverse speed increases, the effect of thermal cycle on the welded joint properties is weakened leading to an improvement in tensile strength and hardness of the welded joint.

\subsection{Effect of process parameters on response variables}

When the tool rotational speed is compared with the tilt angle and traverse speed then the rotational speed is more sensitive to change or increase the tensile strength and micro-hardness of the friction stir welded joint of AA6061 and AA6082 because the heat generation is mainly depended on tool rotational speed, higher tool rotational speed produces higher heat generation [38]. Fig. 9-11 shows the Variation of response parameters and processing parameters of FSW welded joint of AA6061 and AA6082. According to these figures when the tool rotation increases, response parameters (tensile strength, percentage elongation and micro-hardness at nugget zone) also increases at certain limit, whereas when traverse speed increases the response parameters first increases then decreases and when tilt angle in increases, response parameters first decreases then increases at tilt angle $2^{0}$ as shown in fig. 9-11. 

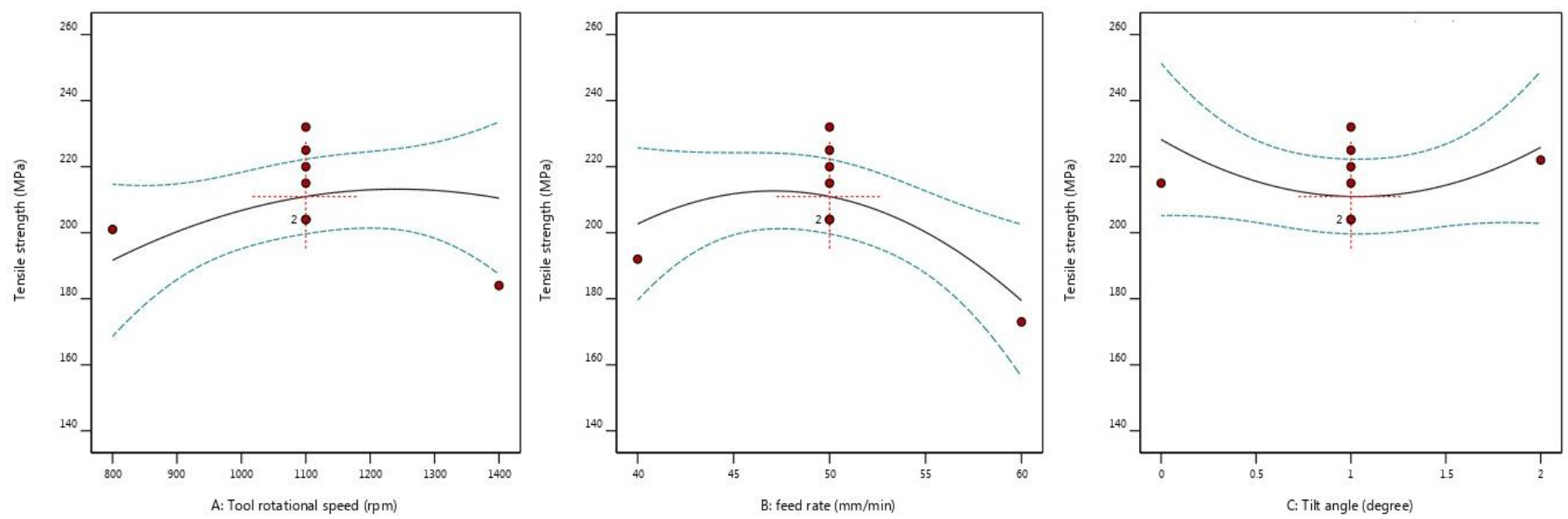

Figure 9: Variation of Tensile strength and processing parameters of welded joint of AA6061 and AA6082
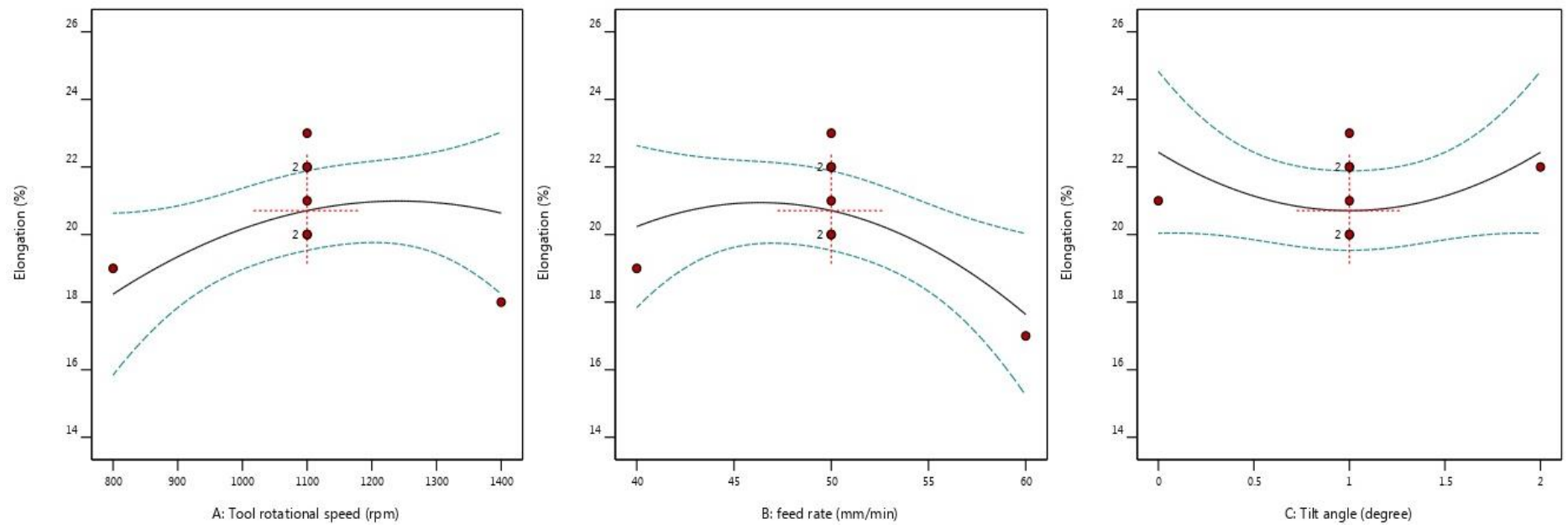

Figure 10: Variation of percentage elongation and processing parameters of welded joint of AA6061 and AA6082
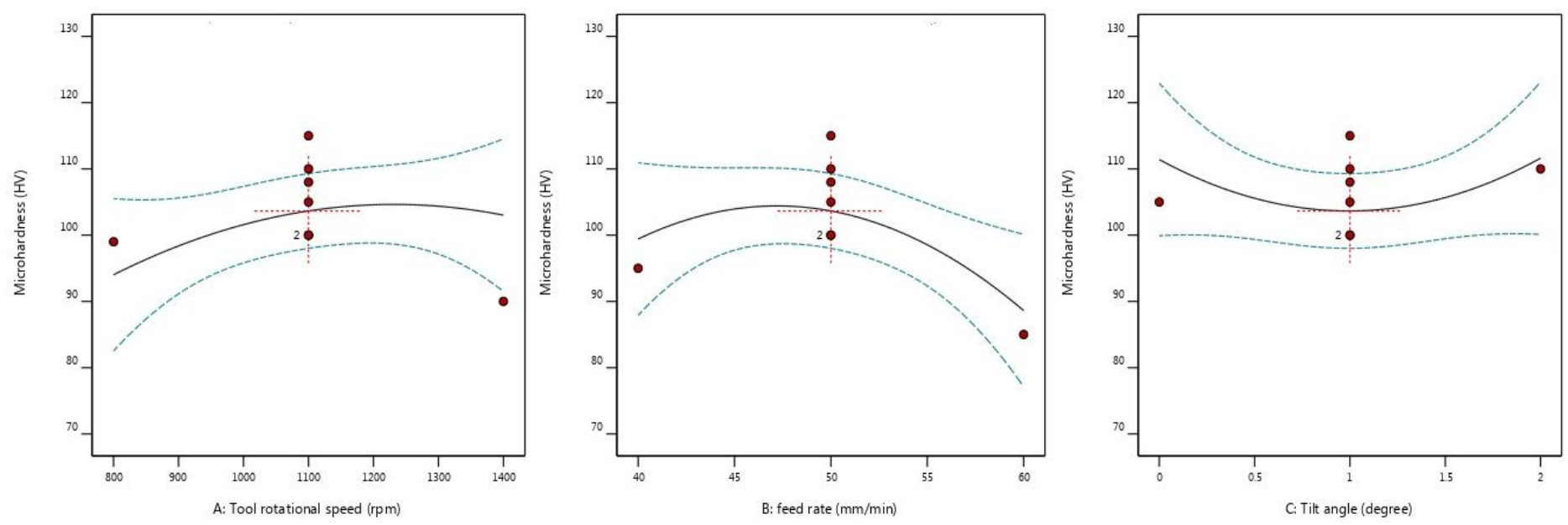

Figure 11: Variation of micro-hardness at nugget zone and processing parameters of welded joint of AA6061 and AA6082 


\section{Conclusions}

The present work was designed to identify the most influencing and optimal friction stir welding process parameters on tensile strength and hardness of welded joint of AA6061 and AA6082 using design expert software. Various combination of processing parameters were opt to investigate the optimum values of tensile strength and micro-hardness at nugget zone. The maximum tensile strength $(236 \mathrm{MPa})$ and micro-hardness $(115 \mathrm{HV})$ were found at tool rotation speed $1400 \mathrm{rpm}$, traverse speed $40 \mathrm{~mm} / \mathrm{min}$ with tilt angle $2^{0}$, whereas minimum tensile strength (165 MPa) was observed at tool rotation speed $800 \mathrm{rpm}$, traverse speed 60 $\mathrm{mm} / \mathrm{min}$ with tilt angle $2^{0}$. In addition, a numerical model and empirical relationship was developed by design expert software between processing parameters (tool rotation speed, traverse speed, and tilt angle) and response surface parameters (tensile strength, percentage elongation and micro-hardness at nugget zone).

\section{References}

[1] M.B.D. Ellis, Joining of aluminiumbased metal matrix composites, Int. Mater. Rev. 41(2) (1996) 41-58.

[2] R.Y. Huang, S.C. Chen, J.C. Huang, Electron and laser beamwelding of high strain rate superplastic Al-6061/SiC composites, Metall. Mater. Trans. A Phys. Metall. Mater. Sci. 32 (10) (2001) 2575-2584.

[3] Cemal Meran, The joint properties of brass plates by friction stir welding, Materials and Design 27 (2006) 719-726.

[4] Hasan Okuyucu, Adem Kurt, Erol Arcaklioglu, Artificial neural network application to the friction stir welding of aluminum plates, Materials and Design 28 (2007) 78-84.

[5] P.M.G.P. Moreira, T. Santos, S.M.O. Tavares, V. Richter-Trummer, P. Vilaça, P.M.S.T. de Castro, Mechanical and metallurgical characterization of friction stir welding joints of AA6061-T6 with AA6082-T6, Materials and Design 30 (2009) 180-187.

[6] Z. Zhang, H.W. Zhang, Numerical studies on the effect of transverse speed in friction stir welding, Materials and Design 30 (2009) 900-907.

[7] Y.C. Chen, K. Nakata, Microstructural characterization and mechanical properties in friction stir welding of aluminum and titanium dissimilar alloys, Materials and Design 30 (2009) 469-474.

[8] Moataz M. Attallah, Hanadi G. Salem, Friction stir welding parameters: a tool for controlling abnormal grain growth during subsequent heat treatment, Materials Science and Engineering A 391 (2005) 51-59.

[9] G. Buffa, J.Hua, R. Shivpuri, L. Fratini, A continuum based fem model for friction stir welding-model development, Materials Science and Engineering A 419 (2006) 389-396.

[10] R. Ueji, H. Fujii, L.Cui, A. Nishioka, K. Kunishige, K. Nog, Friction stir welding of ultrafine grained plain low-carbon steel formed by the martensite process, Materials Science and Engineering A 423 (2006) 324-330.

[11] Husain Mehdi, Mishra R.S (2017b), "Mechanical and microstructure characterization of friction stir welding for dissimilar alloy- A Review." International Journal of Research in Engineering and Innovation, vol-1, issues5, 57-67.

[12] Husain Mehdi, R. S Mishra, Mechanical properties and microstructure studies in Friction Stir Welding (FSW) joints of dissimilar alloy- A Review."' Journal of Achievements in Materials and Manufacturing Engineering, 77 (1) pp.31-40, 2016.

[13] Husain Mehdi, R.S Mishra, Influences of Process Parameter and Microstructural Studies in Friction Stir Welding of Different Alloys: A Review, International Journal of Advanced Production and Industrial Engineering, SI-MM 509, pp. 55-62, 2017.

[14] Husain Mehdi, R.S Mishra, Analysis of Material Flow and Heat Transfer in Reverse Dual Rotation Friction Stir Welding: A Review, International Journal of Steel Structures, vol 19, issue 2, 422-434, 2019.

[15] Husain Mehdi, R.S Mishra, Study of the influence of friction stir processing on tungsten inert gas welding of different aluminum alloy, SN Applied Sciences, (2019) 1:712 | https://doi.org/10.1007/s42452-019-0712-0.
[16] Hidetoshi Fujii, Ling Cui, Nobuhiro Tsuji, Masakatsu Maeda, Kazuhiro Nakata, Kiyoshi Nogi, Friction stir welding of carbon steels, Materials Science and Engineering A 429 (2006) 50-57.

[17] Judy Schneider, Ronald Beshears, Arthur C. Nunes Jr, Interfacial sticking and slipping in the friction stir welding process, Materials Science and Engineering A 435-436 (2006) 297-304.

[18] Seung Hwan C. Park, Yutaka S. Sato, Hiroyuki Kokawa, Kazutaka Okamoto, Satoshi Hirano, Masahisa Inagak, Rapid formation of the sigma phase in 304 stainless steel during friction stir welding, Scripta Materialia 49 (2003) 1175-1180.

[19] L. Ceschini, I. Boromei, G. Minak, A. Morri, Microstructure, tensile and fatigue properties of AA6061/20 vol. $\% \mathrm{Al}_{2} \mathrm{O}_{3 \mathrm{p}}$ friction stir welded joints, Composites: Part A 38 (2007) 1200-1210.

[20] Wang Kuai-she, WU Jia-lei, Wang Wen, ZHOU Long-hai, LIN Zhao-xia, KONG Liang, Underwater friction stir welding of ultrafine grained 2017 aluminum alloy, J. Cent. South Univ. (2012) 19: 2081-2085.

[21] G. Padmanaban , V. Balasubramanian, An experimental investigation on friction stir welding of AZ31B magnesium alloy, Int J Adv Manuf Technol ,(2010), 49, 111-121.

[22] H.W. Zhang, Z. Zhang, J.T. Chen, 3D modeling of material flow in friction stir welding under different process parameters, Journal of Materials Processing Technology, 183, (2007), 62-70.

[23] H. Zhang , S.B. Lin, L. Wu, J.C. Feng, S.L. Ma, Defects formation procedure and mathematic model for defect free friction stir welding of magnesium alloy, Materials and Design ,27, (2006),805-809.

[24] G. Raghu Babu , K. G. K. Murti, G. R. Janardhana, An Experimental Study On The Effect Of Welding Parameters On Mechanical And Microstructural Properties Of Aa 6082-T6 Friction Stir Welded Butt Joints, Arpn Journal Of Engineering And Applied Sciences ,2008 , 3, 68-74.

[25] Manoj Saini , Navneet Arora, Chandan Pandey, Husain Mehdi, Preliminary Studies on Thermal Cycling of Reactor Pressure Vessel Steel'International Journal of Mechanical Engineering, vol.4 issue 2,2014, 51-58.

[26] Manoj Saini, Navneet Arora, Chandan Pandey, Husain Mehdi ,Mechanical Properties of Bimetallic Weld Joint between SA516 Grade 65 Carbon Steel and SS304L for Steam Generator Application, International Journal of Research in Engineering and Technology,vol3 (7), 2014, 39-42.

[27] Husain Mehdi, Shwetanshu Gaurav, Teetu Kumar, Prasoon Sharna, Mechanical Characterization of SA508Gr3 and SS-304L Steel Weldment, International Journal of Advanced Production and Industrial Engineering, 2 (1), pp. 41-46, 2017.

[28] P. Heurtier , M.J. Jones , C. Desrayaud , J.H. Driver , F. Montheillet , D. Allehaux, Mechanical and thermal modelling of Friction Stir Welding, Journal of Materials Processing Technology, 171 ,(2006), 348-357.

[29] H. J. Aval , S. Serajzadeh , A. H. Kokabi, Theoretical and experimental investigation into friction stir welding of AA 5086, Int J Adv Manuf Technol ,(2011), 52, 531-544.

[30] Midling OT, Oosterkamp LD, Bersaas J. Friction stir welding aluminium process and applications. In: Proceedings of the seventh international conference on joints in aluminium, INALCO98; 1998.

[31] Backlund J, Norlin A, Andersson A. Friction stir welding-weld properties and manufacturing techniques. In: Proceedings of the seventh international conference on joints in aluminium, INALCO98; 1998.

[32] Hakan Aydın, Ali Bayram, Agah Uguz, Kemal Sertan Akay, Tensile properties of friction stir welded joints of 2024 aluminum alloys in different heat-treated-state, Materials and Design 30 (2009) 2211-2221.

[33] M.M.Z. Ahmeda, B.P. Wynnea, W.M. Rainfortha, P.L. Threadgill, Microstructure, crystallographic texture and mechanical properties of friction stir welded AA2017A, Mater. Charact. 64 (2012) 107-117.

[34] M.M.Z. Ahmeda, B.P. Wynnea, W.M. Rainfortha, P.L. Threadgill, An investigation of hardness, microstructure and crystallographic texture in thick sectioned friction stir welded AA6082, in: 7th International Friction Stir Welding Symposium, Awaji Island, Japan, 2012.

[35] Frigaard $\varnothing$, Grong $\varnothing$, Midling OT. A process model for friction stir welding of age hardening aluminum alloys. Metall Mater Trans 2001;A32(5):11892000.

[36] Xu WF, Liu JH, Luan GH, Dong CL. Microstructure and mechanical properties of friction stir welded joints in 2219-T6 aluminum alloy. Mater Des 2009;30:3460-7.

[37] Zhang HJ, Liu HJ, Yu L. Microstructure and mechanical properties as a function of rotation speed in underwater friction stir welded aluminum alloy joints. Mater Des 2011;32:4402-7. 
[38] Rajakumar R, Muralidharan C, Balasubramanian V. Influence of frictionstir-welding process and tool parameters on strength properties of AA7075-

T6 aluminium alloy joints [J]. Material Design, 2011, 32: 535-543.

Cite this article as: Hridya Nand Singh, Amit Kaushik, Deepak Juneja, Optimization of process parameters of friction stir welded joint of AA6061 and AA6082 by response surface methodology (RSM), International Journal of Research in Engineering and Innovation Vol-3, Issue-6 (2019), 417-427. https://doi.org/10.36037/IJREI.2019.3610 